\title{
Beneficial Effects of a Specially Designed Home Meal Replacement on Cardiometabolic Parameters in Individuals with Obesity: Preliminary Results of a Randomized Controlled Clinical Trial
}

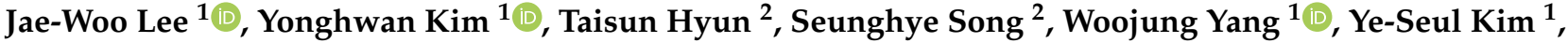 \\ Hyo-Sun You ${ }^{1}$, , Young-Chang Chang ${ }^{3}$, Seung-Ho Shin ${ }^{3}$ and Hee-Taik Kang $1,4, * \mathbb{D}$
}

1 Department of Family Medicine, Chungbuk National University Hospital, Cheongju 28644, Korea; shrimp06111@gmail.com (J.-W.L.); airsantajin@gmail.com (Y.K.); kineto@naver.com (W.Y.); yesul86@naver.com (Y.-S.K.); hyo920@gmail.com (H.-S.Y.)

2 Department of Food and Nutrition, Chungbuk National University, Cheongju 28644, Korea; taisun@chungbuk.ac.kr (T.H.); dmssh95@naver.com (S.S.)

3 Greengrassbio, Incorporated, Chungju 27462, Korea; ycchang@somega3.co.kr (Y.-C.C.); somega3@naver.com (S.-H.S.)

4 Department of Family Medicine, Chungbuk National University College of Medicine, Cheongju 28644, Korea

* Correspondence: kanght0818@gmail.com; Tel.: +82-43-269-6301

Citation: Lee, J.-W.; Kim, Y.; Hyun, T.; Song, S.; Yang, W.; Kim, Y.-S.; You, H.-S.; Chang, Y.-C.; Shin, S.-H.; Kang, H.-T. Beneficial Effects of a Specially Designed Home Meal Replacement on Cardiometabolic Parameters in Individuals with Obesity: Preliminary Results of a Randomized Controlled Clinical Trial. Nutrients 2021, 13, 2171. https://doi.org/10.3390/nu13072171

Academic Editor: Karolina

Szewczyk-Golec

Received: 6 May 2021

Accepted: 22 June 2021

Published: 24 June 2021

Publisher's Note: MDPI stays neutral with regard to jurisdictional claims in published maps and institutional affiliations.

Copyright: (c) 2021 by the authors. Licensee MDPI, Basel, Switzerland. This article is an open access article distributed under the terms and conditions of the Creative Commons Attribution (CC BY) license (https:// creativecommons.org/licenses/by/ $4.0 /)$.

\begin{abstract}
We aimed to investigate if a home meal replacement (HMR), designed with a low $\omega-6 / \omega-3$ fatty acid ratio, improves cardiometabolic parameters, including metabolic syndrome (MetS) in obese individuals. We conducted a monocentric, controlled, randomized crossover trial. The HMR contains higher protein and fat content, lower carbohydrate content, and a lower $\omega 6 \mathrm{FA} / \omega 3 \mathrm{FA}$ ratio than the regular diet. Sixty-four participants were randomized into two groups and switched to the other group following a 4-week intervention. While subjects in the HMR group were provided three HMRs daily, those in the control group were requested to maintain their regular dietary pattern. We conducted paired t-tests, repeated measures analysis of variance, and McNemar tests before and after the intervention. Body mass index (BMI) and weight were lower in the HMR group after adjusting for age, sex, and total energy intake and significantly changed in the between-group differences. The waist circumference, systolic blood pressure, triglycerides, triglyceride-glucose index, and triglyceride to high-density lipoprotein cholesterol ratio were reduced in the HMR group (all $p<0.05$ ). The percentage of subjects with MetS significantly decreased from $39.1 \%$ at baseline to $28.1 \%$ post-intervention $(p=0.035)$. Using the HMR for 4 weeks reduced the BMI, weight, and MetS prevalence in individuals with obesity. This trial was registered at clinicaltrials.gov (NCT04552574).
\end{abstract}

Keywords: omega-3 fatty acids; metabolic syndrome; cardiovascular disease; omega-6 and omega-3 fatty acid ratio; cardiometabolic parameters; obese individuals

\section{Introduction}

Obesity is a global epidemic that has rapidly grown in recent decades [1]. According to the World Health Organization (WHO), more than 13\% (650 million) of adults were obese in 2016 [2]. Obesity is a major risk factor for various noncommunicable diseases (NCDs), such as cardio-cerebrovascular disease, diabetes, osteoarthritis, and dementia, eventually contributing to a decline in both quality of life and life expectancy [3]. Therefore, obesity management plays a key role in preventing and controlling NCDs. The development of the food industry and the increase in single-person households have changed the dietary pattern, such as an increased consumption of more palatable foods or convenience meals that contain more fat and salt [4]. The aforementioned dietary patterns partly contribute to the growing prevalence of obesity. Thus, the WHO recommends a healthy diet with a low 
trans and saturated fat content and a high unsaturated fat content, including essential fatty acids, to avoid unhealthy weight gain [5].

Essential fatty acids that cannot be synthesized in the human body should be ingested to maintain the biological processes [6]. The most well-known essential fatty acids are omega-3 fatty acids (w3FAs), such as alpha-linolenic acid and omega- 6 fatty acids ( $\omega 6 \mathrm{FAs})$, such as linoleic acid. Fatty marine fishes, such as salmon and tuna, are rich in w3FAs, namely, eicosapentaenoic acid (EPA) and docosahexaenoic acid (DHA) [7]. Alpha-linolenic acid is sourced from flaxseeds, pumpkin seeds, green leafy vegetables, nuts, and beans [8] Several studies have reported that a high ratio of $\omega 6 \mathrm{FAs}$ relative to $\omega 3 \mathrm{FAs}$ ( $\omega 6 \mathrm{FA} / \omega 3 \mathrm{FA}$ ratio) is associated with pro-inflammatory responses and an increased risk of NCDs, including cardiovascular diseases and cancers $[9,10]$. The westernized diet comprises a high $\omega 6 \mathrm{FA} / \omega 3 \mathrm{FA}$ ratio (frequently $\geq 10: 1$ ). A previous meta-analysis reported on the association between a higher intake of $\omega 3$ FAs and a lower risk of metabolic syndrome (MetS), compared to $\omega 6$ FAs [11]. Moreover, a diet rich in $\omega 3$ FAs and low in $\omega 6$ FAs may be important determinant in maintaining homeostasis and healthy diet $[5,12]$.

Therefore, we aimed to investigate if a home meal replacement (HMR), designed with an $\omega 6 \mathrm{FA} / \omega 3 \mathrm{FA}$ ratio $<4$, improves cardiometabolic parameters, including MetS, in individuals with obesity as compared to a regular diet.

\section{Materials and Methods}

\subsection{Study Design, Population, and Home Meal Replacement}

We performed this clinical trial using a monocentric, controlled, randomized, crossover design to compare the effects of a HMR, with a $\omega 6 \mathrm{FA} / \omega 3 \mathrm{FA}$ ratio $<4$ [13], and a regular diet (control group) on cardiometabolic parameters and sarcopenia. This current paper is not a final report, is a preliminary report. Additionally, upon completion of the final study, we will report on the primary and secondary outcome measures, including lipid profile and several biomarkers related to sarcopenia. Hereinafter, we will denote the provided foods containing a lower $\omega 6 \mathrm{FA} / \omega 3 \mathrm{FA}$ ratio as the $\omega$-balanced diet.

We recruited cardiometabolically unhealthy participants. However, they had not been treated with medications. The inclusion criteria were as follows: (1) individuals aged $\geq 40$ years; (2) with a body mass index (BMI) ranging between $25 \mathrm{~kg} / \mathrm{m}^{2}$ and $40 \mathrm{~kg} / \mathrm{m}^{2}$, according to the Western Pacific Regional Office of the World Health Organization's criteria for obesity [14]; (3) with a systolic blood pressure (SBP) $\geq 100 \mathrm{mmHg}$ and $<180 \mathrm{mmHg}$ and a diastolic blood pressure (DBP) $\geq 70 \mathrm{mmHg}$ and $<110 \mathrm{mmHg}$; and (4) with a waist circumference $\geq 90 \mathrm{~cm}$ and $\geq 85 \mathrm{~cm}$ in males and females, respectively. In contrast, the exclusion criteria were as follows: (1) individuals with a medical history of hypertension, diabetes, dyslipidemia, or cardio-cerebrovascular diseases; (2) those using anti-hypertensive, antidiabetic, or anti-dyslipidemic drugs; (3) those consuming weight-reducing medications; (4) those consuming 14 and 7 drinks of alcohol in 1 week for males and females, respectively; (5) current smokers; and (6) those with abnormal laboratory results (aspartate aminotransferase $>100 \mathrm{IU} / \mathrm{L}$, alanine aminotransferase $>100 \mathrm{IU} / \mathrm{L}$, total cholesterol $>300 \mathrm{mg} / \mathrm{dL}$, triglycerides (TG) $>400 \mathrm{mg} / \mathrm{dL}$, low-density lipoprotein cholesterol (LDL-C) $>190 \mathrm{mg} / \mathrm{dL}$, a white blood cell count $>10,000$ or $<1500$ cells $/ \mu \mathrm{L}$, or high-sensitive C-reactive protein $>5 \mathrm{mg} / \mathrm{L}$ ). We initially recruited 90 participants. Following the baseline interview and health checkup, we excluded 18 participants. Eight participants were further excluded because they wanted to withdraw their consent or lived too far away to deliver the HMR. We eventually included 64 participants in the study (Figure 1). The study participants were randomly allocated to two groups (initially: 30 and 34 participants in the HMR group and control group, respectively). The groups were switched following the 4-week intervention (after crossover: 34 and 30 participants in the HMR group and control group, respectively). We set the baseline data as those before each 4-week intervention. Thus, we measured the baseline variables at visit 1 (initial enrollment) and visit 3 (after wash-out for 2 weeks) (Figure 1). 


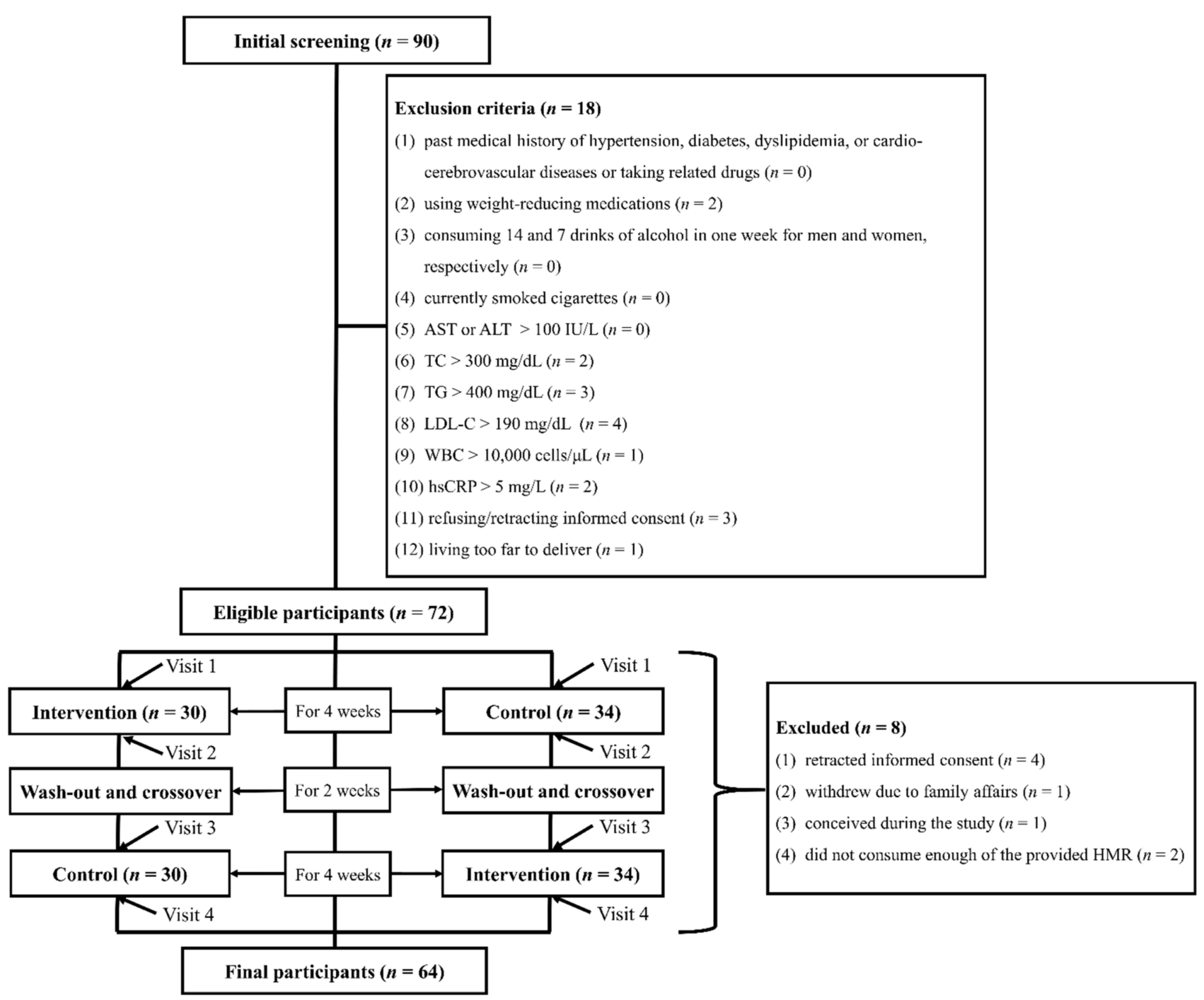

Figure 1. Flowchart of participant exclusion. Abbreviations: AST, aspartate aminotransferase; ALT, alanine aminotransferase; TC, total cholesterol; TG, triglycerides; LDL-C, low-density lipoprotein cholesterol; WBC, white blood cell count; hsCRP, high-sensitivity C-reactive protein.

The HMR was designed with an $\omega 6 \mathrm{FA} / \omega 3 \mathrm{FA}$ ratio $<4$, prepared by professional dietitians and produced by Greengrassbio, Inc. We provided HMRs to the HMR group for 4 weeks. Breakfast was served as a convenience meal, such as milk butter porridge, beef seaweed soup, beef vegetable porridge, and yogurt. Lunch and dinner were all cooked and served in the form of lunch boxes, allowing for easy heating in a microwave. We recommended subjects to avoid eating other foods other than HMR during intervention period. The provided HMR was reanalyzed in the laboratory and verified by well-trained dietitians. We recommended the control group to continue their regular diet for 4 weeks.

This study was approved by the Institutional Review Board of the Chungbuk National University Hospital (CBNUH 2020-06-021-004), and followed the guidelines of the Declaration of Helsinki (1975). All participants provided written informed consent. In addition, they could withdraw their participation at any time. Clinical trial investigators and supporting research staff at the Clinical Trials Office of the Chungbuk National University Hospital collected the data and supervised the clinical trial monitoring. The ClinicalTrials.gov identifier for this study is NCT04552574. 


\subsection{Dietary Intake Data, Energy, and Nutrient Intake}

A trained dietitian collected the dietary intake data from all participants using the $24 \mathrm{~h}$ recall method at visit 1 and, thereafter, a photo-based food diary method. The dietitian requested each participant to recall and describe in detail all the food and beverages consumed on the previous day. Moreover, instructions and examples were provided for the photo-based diary. Each participant was requested to capture food photographs using a smartphone, before and after consumption. These photographs were then transferred using a mobile service platform. We were not able to assess dietary intake for the control and intervention groups at the same time points. Food diaries were collected during the entire intervention period from the HMR group, and over two non-consecutive days, whether weekend days or weekdays, during the same period from the control group. This was because the control group was unable to maintain continuous contact during the entire intervention period.

The abovementioned dietitian determined the name and amount of food consumed by each participant using the food images before and after eating. The energy and nutrient intake were estimated using the Computer-Aided Nutritional Analysis program (CAN-Pro, Korean Nutrition Society, Seoul, Korea) version 5.0, developed by the Korean Nutrition Society [15].

\subsection{Cardiometabolic Parameters}

We defined MetS according to the National Cholesterol Education Program Adult Treatment Panel III for Asian-Americans and the Korean Clinical Practice Guideline of Prevention and Treatment for Metabolic Syndrome [16,17]. MetS was diagnosed when a subject met three or more of the following criteria: (1) waist circumference $\geq 90 \mathrm{~cm}$ and $\geq 85 \mathrm{~cm}$ in males and females, respectively; (2) $\mathrm{SBP} \geq 130 \mathrm{mmHg}$, DBP $\geq 85 \mathrm{mmHg}$; (3) fasting plasma glucose $\geq 100 \mathrm{mg} / \mathrm{dL}$; (4) TG $\geq 150 \mathrm{mg} / \mathrm{dL}$; and (5) high-density lipoprotein cholesterol (HDL-C) $<40 \mathrm{mg} / \mathrm{dL}$ and $<50 \mathrm{mg} / \mathrm{dL}$ in males and females, respectively. We calculated the metabolic parameters, such as the homeostasis model assessment-estimated insulin resistance (HOMA-IR) [18], TG-glucose (TyG) index [19], and TG/HDL-C ratio [20] using the following equations:

$$
\begin{gathered}
\text { HOMA-IR }=\text { [fasting insulin }(\mathrm{mU} / \mathrm{mL}) \times \text { fasting glucose }(\mathrm{mg} / \mathrm{dL}) / 405] \\
\text { TyG index }=\text { Ln [fasting TG }(\mathrm{mg} / \mathrm{dL}) \times \text { fasting blood glucose }(\mathrm{mg} / \mathrm{dL}) / 2 \text { ] }
\end{gathered}
$$

\subsection{Measurements of Anthropometric and Laboratory Variables}

We collected personal lifestyle information, anthropometric measurements, and blood for laboratory testing. Height $(\mathrm{cm})$ and weight $(\mathrm{kg})$ were measured with subjects wearing light indoor clothing without shoes, using an automated stadiometer (DS-102, DONG SAHN JENIX Co., Seoul, 114 Korea). We calculated the BMI $\left(\mathrm{kg} / \mathrm{m}^{2}\right)$ by dividing the weight by the square of the height. Waist circumference $(\mathrm{cm})$ was measured at the umbilicus level with the subject standing upright using an elastic measuring tape. We recorded the blood pressure $(\mathrm{mmHg})$ on the right arm using an automatic blood pressure monitor (EASY X 800R, Jawon Medical, Seoul, Korea), with the subjects seated after resting for at least $10 \mathrm{~min}$.

Moreover, we measured the following laboratory variables: total cholesterol, TG, HDL-C, LDL-C, glycated hemoglobin (HbA1C), glucose, and insulin. Blood samples were collected after at least $8 \mathrm{~h}$ of fasting. We measured the total cholesterol and TG by means of the colorimetry method using a Cobas c502 (HITACHI, Tokyo, Japan). Moreover, we analyzed the HDL-C, LDL-C, and glucose levels by means of the enzymatic method using a Cobas c502 (HITACHI, Tokyo, Japan). The HbA1C was derived by means of the turbidimetric immunoassay method using a Cobas c513 (HITACHI, Tokyo, Japan). In addition, we measured insulin levels by means of an electrochemiluminescence immunoassay method using an e801 (Roche, Tokyo, Japan). 


\subsection{Statistical Analysis}

The statistical summary is presented as number (\%) and as mean \pm standard deviation (SD) for the categorical and continuous variables, respectively. We performed paired t-tests to compare the means for continuous variables, before and after the intervention. We used repeated-measures analysis of variance to determine the difference between the groups, with time (before vs. after) as a within-subject factor and group (intervention vs. control) as a between-subject factor. In addition, the adjusted $p$-values were calculated by adjusting for age, sex, and total energy intake to describe the differences, for each variable, between the groups. We applied mixed models using the intervention group and visit time as fixed effects, and the subject as a random effect. We conducted the McNemar test to investigate a change in proportion for the paired nominal data of MetS and its individual components. All $p$-values were two-sided and the statistical significance was set at $<0.05$. We used the SAS enterprise guide version 7.1 (SAS Inc., Cary, NC, USA) for the analyses.

\section{Results}

Table 1 summarizes the baseline characteristics before the intervention (at visit 1 and visit 3 ). The mean age of the study participants was 46.5 years, and $25 \%$ were men. The mean BMI and waist circumference of the participants were $28.1 \mathrm{~kg} / \mathrm{m}^{2}$ and $91.8 \mathrm{~cm}$, respectively. The average SBP and DBP were $126.6 \mathrm{mmHg}$ and $81.5 \mathrm{mmHg}$, respectively. The mean total cholesterol, TG, and LDL-C levels were $203.9 \mathrm{mg} / \mathrm{dL}, 134.9 \mathrm{mg} / \mathrm{dL}$, and $135.5 \mathrm{mg} / \mathrm{dL}$, respectively. Moreover, the fasting glucose levels were $93.8 \mathrm{mg} / \mathrm{dL}$.

Table 1. Baseline characteristics of study subjects before the intervention.

\begin{tabular}{lc}
\hline & Total \\
\hline N & 128 \\
Age, years & $46.5 \pm 5.6$ \\
Men, $n$ (\%) & $32(25.0)$ \\
Height, cm & $162.3 \pm 8.0$ \\
Weight, kg & $74.2 \pm 9.6$ \\
BMI, kg/m ${ }^{2}$ & $28.1 \pm 2.9$ \\
Waist circumference, cm & $91.8 \pm 6.9$ \\
${ }^{5}$ SBP, mmHg & $126.6 \pm 11.9$ \\
${ }^{1}$ DBP, mmHg & $81.5 \pm 10.2$ \\
Total cholesterol, mg/dL & $203.9 \pm 35.0$ \\
${ }^{6}$ TG, mg/dL & $134.9 \pm 67.6$ \\
${ }^{3} \mathrm{HDL}-\mathrm{C}, \mathrm{mg} / \mathrm{dL}$ & $54.4 \pm 13.9$ \\
4 LDL-C, mg/dL & $135.5 \pm 29.7$ \\
${ }^{2} \mathrm{HbA1c} \%$ & $5.5 \pm 0.4$ \\
Glucose, mg/dL & $93.8 \pm 14.0$ \\
Insulin, IU/mL & $9.3 \pm 5.8$ \\
\hline
\end{tabular}

${ }^{1}$ DBP, diastolic blood pressure; ${ }^{2} \mathrm{HbA1c}$, glycated hemoglobin; ${ }^{3} \mathrm{HDL}-\mathrm{C}$, high-density lipoprotein cholesterol; ${ }^{4}$ LDL-C, low-density lipoprotein cholesterol; ${ }^{5}$ SBP, systolic blood pressure; and ${ }^{6}$ TG, triglycerides.

Table 2 outlines the differences in nutrient intake, before and during the clinical trial in the two groups. The total energy intake at baseline was $1745.5 \mathrm{kcal} / \mathrm{d}$ and $1766.6 \mathrm{kcal} / \mathrm{d}$ in the HMR group and control group, respectively. During the trial, the HMR group consumed significantly more energy, carbohydrates, proteins, fats, w3FAs, and w6FAs than that at baseline (all $p<0.05$ ). During intervention period, the mean of an $\omega 6 \mathrm{FA} / \omega 3 \mathrm{FA}$ ratio was 4.90 (standard deviation 0.04), median 4.90 (interquartile range, 4.88-4.94), the minimum 4.80 , and the maximum 5.03 in HMR group. The standard deviation of the $\omega 6 \mathrm{FA} / \omega 3 \mathrm{FA}$ ratio of subjects before the intervention was high, but the standard deviation was low during the intervention period in the HMR group. In contrast, the control group consumed similar amounts of total energy, macronutrients, and fatty acids. The HMR group consumed the diet with a lower $\omega 6 \mathrm{FA} / \omega 3 \mathrm{FA}$ ratio during than before the trial $(12.2$ vs. $4.9, p<0.001)$. 
Table 2. Nutrient intake during the intervention.

\begin{tabular}{|c|c|c|c|c|c|c|c|c|}
\hline & \multicolumn{3}{|c|}{ Home Meal Replacement } & \multicolumn{3}{|c|}{ Control Diet } & \multicolumn{2}{|c|}{ Between-Group Differences } \\
\hline & Before & During & $p$-Value & Before & During & $p$-Value & Before & During \\
\hline Total energy, kcal/d & $1745.5 \pm 519.8$ & $2050.8 \pm 189.4$ & $<0.001$ & $1766.6 \pm 447.6$ & $1705.9 \pm 307.9$ & 0.290 & 0.807 & $<0.001$ \\
\hline Carbohydrates, g/d & $256.5 \pm 85.0$ & $221.5 \pm 18.9$ & 0.001 & $240.6 \pm 75.5$ & $242.6 \pm 48.6$ & 0.833 & 0.265 & 0.002 \\
\hline Protein, g/d & $63.7 \pm 25.1$ & $100.1 \pm 11.2$ & $<0.001$ & $67.4 \pm 24.0$ & $64.9 \pm 15.5$ & 0.476 & 0.116 & $<0.001$ \\
\hline Fat, g/d & $48.8 \pm 21.7$ & $87.7 \pm 9.6$ & $<0.001$ & $55.0 \pm 22.3$ & $49.6 \pm 15.3$ & 0.086 & 0.407 & $<0.001$ \\
\hline${ }^{1} \omega 3 \mathrm{FA}, \mathrm{g} / \mathrm{d}$ & $0.5 \pm 0.7$ & $2.0 \pm 0.3$ & $<0.001$ & $0.4 \pm 0.6$ & $0.8 \pm 1.1$ & 0.050 & 0.975 & $<0.001$ \\
\hline${ }^{2} \omega 6 \mathrm{FA}, \mathrm{g} / \mathrm{d}$ & $3.5 \pm 4.9$ & $9.6 \pm 1.2$ & $<0.001$ & $2.8 \pm 2.9$ & $3.6 \pm 2.5$ & 0.094 & 0.324 & $<0.001$ \\
\hline$\omega 6 \mathrm{FA} / \omega 3 \mathrm{FA}$ ratio & $12.2 \pm 9.5$ & $4.9 \pm 0.0$ & $<0.001$ & $10.6 \pm 7.6$ & $9.2 \pm 5.6$ & 0.200 & 0.309 & $<0.001$ \\
\hline
\end{tabular}

${ }^{1} \omega 3 \mathrm{FA}$, omega-3 fatty acid; ${ }^{2} \omega 6 \mathrm{FA}$, omega- 6 fatty acid; $p$-values were calculated by paired $\mathrm{t}$-test in within group and $t$-test in between group; $\omega 6 \mathrm{FA} / \omega 3 \mathrm{FA}$ ratio, the average value of each subjects' calculated ratio (ingested $\omega 6 \mathrm{FA} /$ ingested $\omega 3 \mathrm{FA}$ ).

Table 3 compares the cardiometabolic parameters, before and after the intervention in both groups. When comparing the within-group mean values, the BMI, body weight, waist circumference, SBP, DBP, TG, HbA1c, TyG index, and TG/HDL ratio significantly decreased after 4 weeks (all $p<0.05$ ) in the HMR group. However, only DBP and HbA1c improved in the control group. Regarding the between-group differences in parameters, the mean BMI and body weight significantly changed between before and after the trial (time $x$ group interaction). Nonetheless, there were no other differences between the groups in the interaction between group and time. The abovementioned statistical differences persisted even after adjusting for age and total energy intake (all $p<0.05)$.

Table 3. Differences in the cardiometabolic parameters after the intervention.

\begin{tabular}{|c|c|c|c|c|c|c|c|c|c|c|c|}
\hline & \multicolumn{4}{|c|}{ HMR } & \multicolumn{4}{|c|}{ Control (Regular Diet) } & \multicolumn{3}{|c|}{$\begin{array}{l}\text { Between-Group } \\
\text { Differences }\end{array}$} \\
\hline & Before & After & Difference & $p^{+}$ & Before & After & Difference & $p^{+}$ & $p^{*}$ & $p^{\$}$ & $p^{\#}$ \\
\hline BMI, $\mathrm{kg} / \mathrm{m}^{2}$ & $28.2 \pm 2.8$ & $28.0 \pm 2.9$ & $-0.2 \pm 0.4$ & $<0.001$ & $28.1 \pm 2.9$ & $28.0 \pm 3.0$ & $-0.1 \pm 0.4$ & 0.218 & 0.016 & 0.044 & 0.034 \\
\hline Weight, $\mathrm{kg}$ & $74.4 \pm 9.7$ & $73.7 \pm 9.6$ & $-0.6 \pm 1.2$ & $<0.001$ & $74.0 \pm 9.6$ & $73.9 \pm 9.7$ & $-0.1 \pm 1.0$ & 0.406 & 0.008 & 0.019 & 0.022 \\
\hline${ }^{10} \mathrm{WC}, \mathrm{cm}$ & $92.1 \pm 7.2$ & $90.4 \pm 7.0$ & $-1.7 \pm 3.5$ & $<0.001$ & $91.7 \pm 6.8$ & $91.2 \pm 7.7$ & $-0.7 \pm 2.9$ & 0.060 & 0.096 & 0.452 & 0.093 \\
\hline${ }^{6} \mathrm{SBP}, \mathrm{mmHg}$ & $126.3 \pm 11.3$ & $123.3 \pm 10.7$ & $-3.0 \pm 8.0$ & 0.004 & $126.8 \pm 12.5$ & $125.8 \pm 12.1$ & $-0.8 \pm 13.0$ & 0.645 & 0.256 & 0.116 & 0.299 \\
\hline${ }^{1} \mathrm{DBP}, \mathrm{mmHg}$ & $81.1 \pm 10.7$ & $79.2 \pm 9.7$ & $-1.9 \pm 6.4$ & 0.019 & $81.8 \pm 9.8$ & $79.2 \pm 8.4$ & $-2.4 \pm 8.9$ & 0.036 & 0.731 & 0.652 & 0.717 \\
\hline $7 \mathrm{TC}, \mathrm{mg} / \mathrm{dL}$ & $205.1 \pm 35.7$ & $206.0 \pm 36.1$ & $0.9 \pm 20.5$ & 0.729 & $202.6 \pm 34.6$ & $204.3 \pm 36.1$ & $1.7 \pm 19.3$ & 0.487 & 0.821 & 0.619 & 0.835 \\
\hline${ }^{8} \mathrm{TG}, \mathrm{mg} / \mathrm{dL}$ & $134.1 \pm 64.6$ & $115.6 \pm 48.4$ & $-18.5 \pm 55.9$ & 0.010 & $135.7 \pm 71.0$ & $130.2 \pm 69.3$ & $-5.6 \pm 53.4$ & 0.408 & 0.183 & 0.230 & 0.175 \\
\hline${ }^{3} \mathrm{HDL}-\mathrm{C}, \mathrm{mg} / \mathrm{dL}$ & $54.0 \pm 14.4$ & $54.5 \pm 13.5$ & $0.6 \pm 6.4$ & 0.461 & $54.8 \pm 13.7$ & $54.1 \pm 13.7$ & $-0.7 \pm 5.8$ & 0.336 & 0.232 & 0.172 & 0.221 \\
\hline${ }^{5} \mathrm{LDL}-\mathrm{C}, \mathrm{mg} / \mathrm{dL}$ & $137.2 \pm 31.7$ & $138.3 \pm 32.3$ & $1.1 \pm 21.2$ & 0.134 & $133.9 \pm 27.9$ & $137.0 \pm 32.0$ & $3.0 \pm 18.0$ & 0.757 & 0.578 & 0.559 & 0.598 \\
\hline${ }^{2} \mathrm{HbA} 1 \mathrm{c}, \%$ & $5.5 \pm 0.4$ & $5.4 \pm 0.4$ & $-0.0 \pm 0.1$ & $<0.001$ & $5.5 \pm 0.4$ & $5.5 \pm 0.4$ & $0.0 \pm 0.1$ & 0.033 & 0.214 & 0.402 & 0.247 \\
\hline Glucose, mg/dL & $93.9 \pm 15.4$ & $95.1 \pm 13.4$ & $1.2 \pm 8.3$ & 0.138 & $93.7 \pm 12.5$ & $94.1 \pm 11.1$ & $0.4 \pm 7.9$ & 0.796 & 0.579 & 0.855 & 0.591 \\
\hline Insulin, IU/mL & $9.2 \pm 5.9$ & $8.9 \pm 5.8$ & $-0.3 \pm 5.1$ & 0.615 & $9.4 \pm 5.7$ & $9.4 \pm 4.5$ & $0.1 \pm 4.3$ & 0.902 & 0.641 & 0.168 & 0.641 \\
\hline${ }^{4}$ HOMA-IR & $2.3 \pm 2.1$ & $2.1 \pm 1.5$ & $-0.1 \pm 1.6$ & 0.504 & $2.2 \pm 1.7$ & $2.2 \pm 1.3$ & $-0.0 \pm 1.1$ & 0.999 & 0.576 & 0.125 & 0.559 \\
\hline${ }^{9}$ TyG index & $8.6 \pm 0.5$ & $8.5 \pm 0.4$ & $-0.1 \pm 0.4$ & 0.002 & $8.6 \pm 0.5$ & $8.6 \pm 0.5$ & $-0.0 \pm 0.4$ & 0.829 & 0.260 & 0.341 & 0.266 \\
\hline TG/HDL-C ratio & $2.8 \pm 1.9$ & $2.3 \pm 1.5$ & $-0.5 \pm 1.6$ & 0.032 & $2.8 \pm 2.1$ & $2.7 \pm 1.9$ & $-0.1 \pm 1.3$ & 0.335 & 0.156 & 0.116 & 0.142 \\
\hline
\end{tabular}

${ }^{+} p$-values were calculated using a paired $t$-test; ${ }^{*} p$-values refer to the level of significance of the time $\times$ group interaction of repeatedmeasures analysis of variance (RM ANOVA), with time (before vs. after) as the within-subject factor and group (intervention vs. control) as the between-subject factor; ${ }^{\$} p$-values were adjusted for age, sex, and total energy intake; ${ }^{\#} p$-values were calculated using the mixed-model analysis as the within-subject factor and group (intervention vs. control) as the between-subject factor; ${ }^{1}$ DBP, diastolic blood pressure; ${ }^{2} \mathrm{HbA1c}$, glycated hemoglobin; ${ }^{3} \mathrm{HDL}-\mathrm{C}$, high-density lipoprotein cholesterol; ${ }^{4} \mathrm{HOMA}-\mathrm{IR}$, homeostasis model assessment-estimated insulin resistance; ${ }^{5} \mathrm{LDL}-\mathrm{C}$, low-density lipoprotein cholesterol; ${ }^{6} \mathrm{SBP}$, systolic blood pressure; ${ }^{7} \mathrm{TC}$, total cholesterol; ${ }^{8} \mathrm{TG}$, triglycerides; ${ }^{9} \mathrm{TyG}$, TG glucose; and ${ }^{10} \mathrm{WC}$, waist circumference.

Figures 2 and 3 depict the percentage of subjects with MetS and its components, before and after the trial. The initial percentage of subjects with MetS was 39.1\% in both groups. After 4 weeks, the percentage significantly reduced to $28.1 \%$ only in the HMR group $(p=0.035)$. Despite a decrease in the control group, the change was statistically insignificant $(p=0.593)$. Among the MetS components, the proportion of meeting criteria for hypertriglyceridemia ( $T G \geq 150 \mathrm{mg} / \mathrm{dL}$ ) significantly decreased from $34.4 \%$ to $20.3 \%$ in the HMR group $(p=0.020)$ (Figure 3$)$. 
Metabolic syndrome (\%)

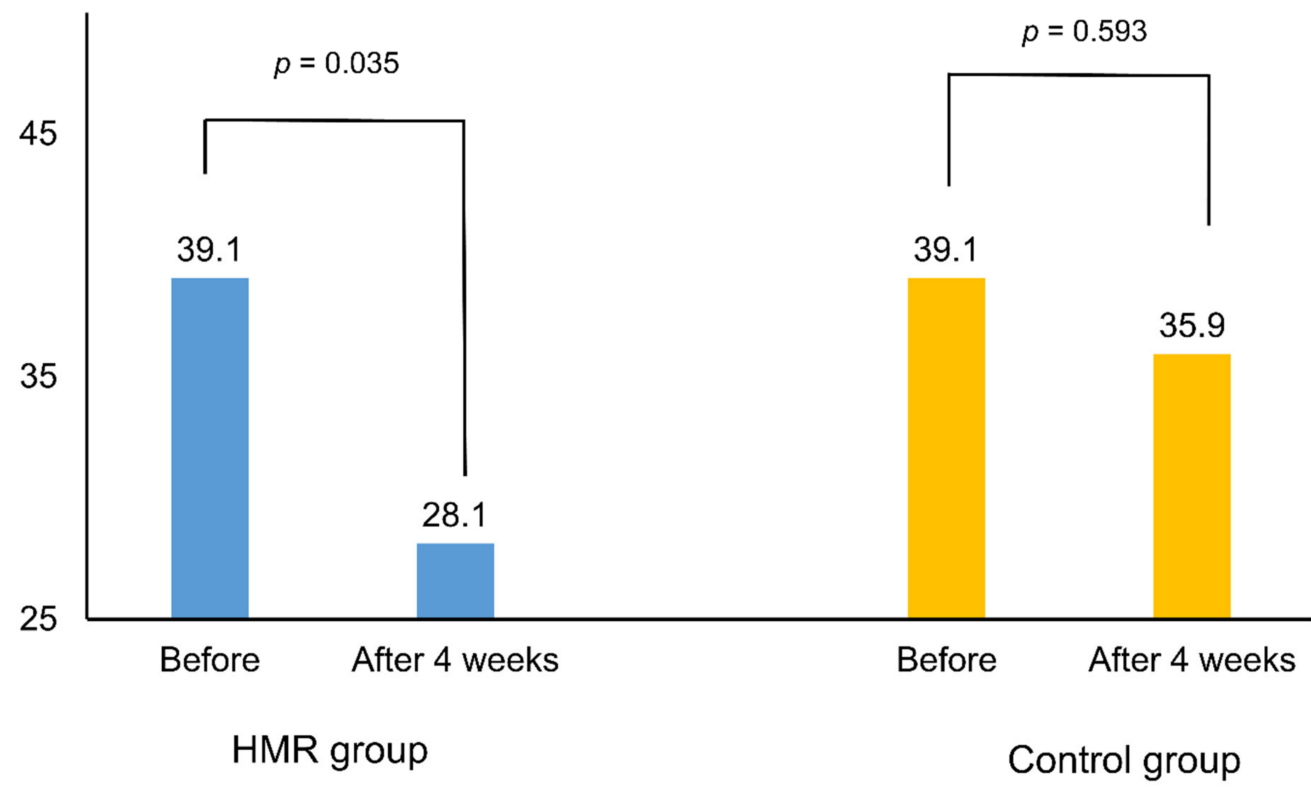

Figure 2. Proportion of subjects meeting metabolic syndrome criteria before and after the intervention according to diet group. $p$-values were calculated using the McNemar test. Abbreviations: HMR, home meal replacement.

\section{Proportion of meeting criteria for each component}

$(\%)$

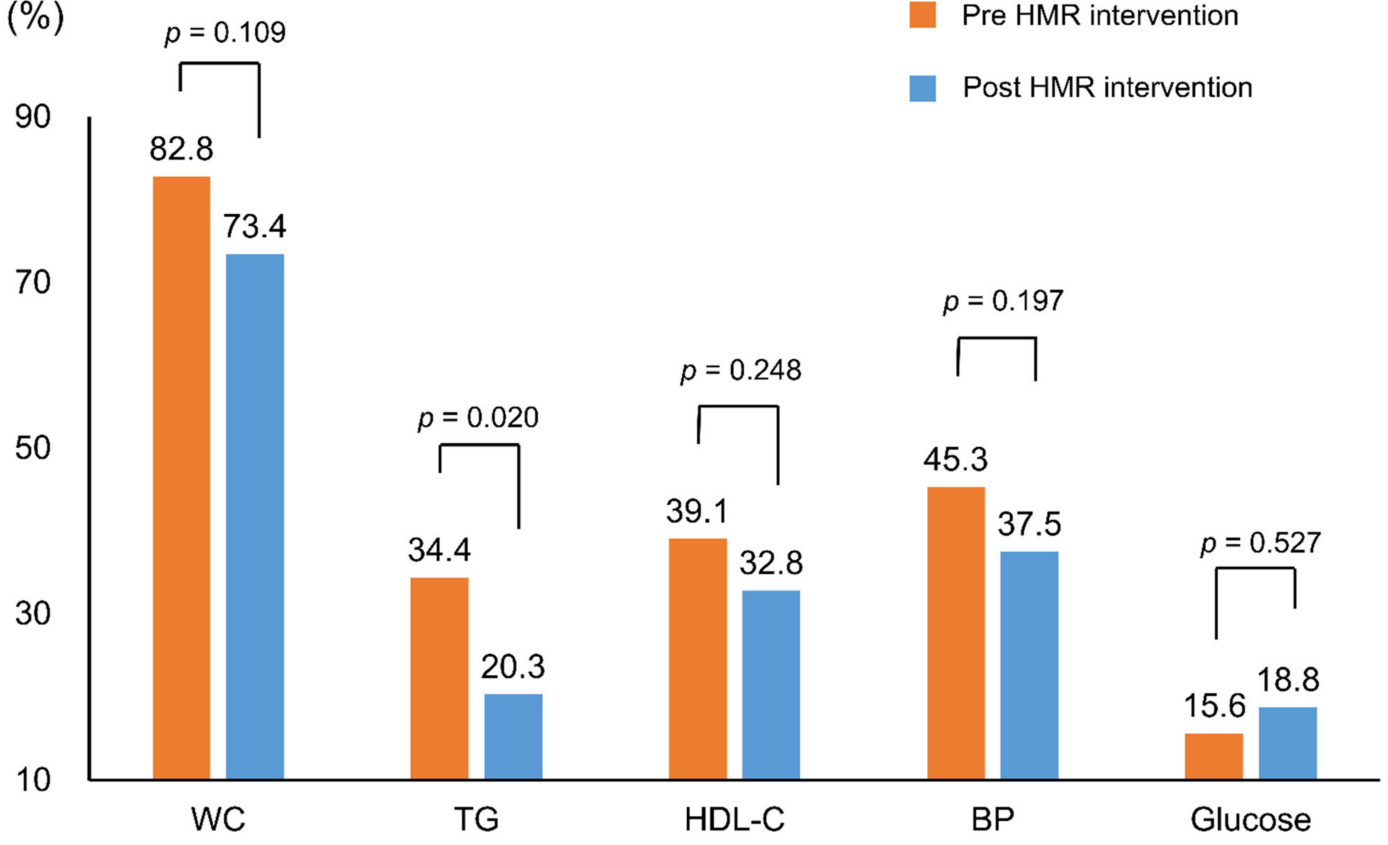

Figure 3. Proportion meeting criteria for each component of metabolic syndrome in intervention group. $p$-values were calculated using the McNemar test; criteria for each component: Central obesity (WC $\geq 90 \mathrm{~cm}$ in men and $\geq 85 \mathrm{~cm}$ in women), hyperglycemia (IFG $\geq 100 \mathrm{mg} / \mathrm{dL}$ ), hypo-HDL-cholesterolemia (HDL-C $<40 \mathrm{mg} / \mathrm{dL}$ in men and $<50 \mathrm{mg} / \mathrm{dL}$ in women), hypertriglyceridemia (TG $\geq 150 \mathrm{mg} / \mathrm{dL}$ ), and high BP (SBP $\geq 130 \mathrm{mmHG}$ or DBP $\geq 85 \mathrm{mmHg}$ ); Abbreviations: HMR, home meal replacement; WC, waist circumference; TG, triglycerides; HDL-C, high-density lipoprotein cholesterol; BP, blood pressure. 


\section{Discussion}

We aimed to examine if the HMR, designed with an $\omega 6 \mathrm{FA} / \omega 3 \mathrm{FA}$ ratio $<4$, improves cardiometabolic parameters in apparently healthy individuals with obesity. Several cardiometabolic parameters, such as the BMI, body weight, waist circumference, SBP, DBP, triglycerides, HbA1c, TyG index, and TG/HDL ratio improved after 4 weeks in the HMR group. The BMI and body weight were notably lower in the HMR group than in the control group. The results remained significant following adjustment for age, sex, and total energy intake. In addition, the percentage of subjects with MetS significantly decreased after the intervention.

Essential fatty acids, such as $\omega 6$ FAs and $\omega 3$ FAs, are not synthesized in the human body; thus, they must be obtained from the diet $[6,12]$. The two families of $\omega 6 \mathrm{FAs}$ and $\omega 3 \mathrm{FAs}$ are metabolized and interconverted using several common enzymes, such as desaturase and elongase $[9,10,12]$. The metabolic competition between $\omega 6 \mathrm{FAs}$ and $\omega 3 \mathrm{FAs}$ could also affect downstream molecule formation of prostaglandin, thromboxane, and leukotrienes. For example, EPA competes with arachidonic acid for cyclooxygenase and lipoxygenase enzymes during prostaglandin and leukotriene synthesis [12]. Arachidonic acid is converted to more proinflammatory, aggregatory, and vasodilatory molecules, such as leukotriene A4, prostaglandin E2, and thromboxane A2 [21]. In contrast, if the amount of EPA and DHA is relatively more ingested than arachidonic acids, molecules that are less proinflammatory and antiaggregatory are more likely to be synthesized due to competitive metabolism $[10,12,22]$. Thus, w3FAs exert a positive impact on health by reducing vasoconstriction, platelet aggregation, atherosclerotic plaque formation, and inflammation [7].

Despite inadequate information on the pathophysiology of MetS, it is a cluster of cardiometabolic dysfunction, including abdominal obesity, glucose intolerance, dyslipidemia, and insulin resistance-mediated hypertension [16]. A few meta-analyses have suggested that $\omega 3$ FAs might reduce the risk of MetS $[11,23]$. We found that the HMR with higher protein, higher fat, and lower $\omega 6 \mathrm{FA} / \omega 3 \mathrm{FA}$ ratio reduced the percentage of subjects with MetS as compared to the control diet, similar to previous studies. In particular, using the HMR for 4 weeks decreased hypertriglyceridemia among the individuals with MetS components. Numerous human studies have supported the finding that sufficient intake of $\omega 3$ FAs lowers the blood TG levels through endogenous TG synthesis and subsequently, acceleration of chylomicron TG clearance [24]. In addition to the TG-lowering effect, w3FAs could reduce the blood pressure by decreasing angiotensin-converting enzymes in the aorta [25]. Moreover, they can improve insulin resistance through the modulation of peroxisome proliferator-activated receptor alpha [26]. In contrast, w6FAs can possibly increase the risk of chronic disease through eicosanoid-mediated inflammatory processes [10,27]. Eicosanoids contribute to the formation of thrombi and atheromas, allergic responses, inflammation, and cell proliferation [27]. Thus, an w6FA-rich diet can exert pro-thrombogenic and pro-aggregatory effects and cause vasoconstriction [10]. However, some epidemiological studies have reported that $\omega 6 \mathrm{FAs}$ do not increase the risk of MetS [28,29], or that $\omega 6 \mathrm{FA}$ intake reduces inflammation and improves insulin resistance [30-32].

There have been several clinical trials on the effects of $\omega 3$ FA on cardiometabolic disease and related markers [13,33-39]. Some studies have reported beneficial effects [13,33-35] whereas others [36-39] have reported neutral or null effects. In previous studies conducted among patients with diabetes, $\omega 3$ FA supplementation was found not to improve coagulation, inflammatory status [40], or endothelial function [41]. However, a prospective, randomized clinical trial revealed that an alpha-linolenic acid-rich Mediterranean diet comprising a $\omega 6 \mathrm{FA} / \omega 3 \mathrm{FA}$ ratio of approximately $4 / 1$ decreased the overall mortality by $70 \%$ for secondary prevention of cardiovascular disease [13]. Most other w3FA supplementation clinical trials did not alter the intake of other fatty acids; specifically, they did not attempt to reduce the intake of w6FAs. Thus, the inconsistent previous findings of fatty acid clinical studies on cardiometabolic health may be the result of failure to adjust 
the $\omega 6 \mathrm{FA} / \omega 3 \mathrm{FA}$ ratio. The $\omega 6 \mathrm{FA} / \omega 3 \mathrm{FA}$ ratio may have the potential to play a role in preventing cardiometabolic diseases and MetS [9-11].

In the present study, the mean w6FA intake in the HMR group increased from $3.5 \mathrm{~g} / \mathrm{d}$ before the intervention to $9.6 \mathrm{~g} / \mathrm{d}$ during the intervention. In contrast, we observed an insignificant increase from 2.8 to $3.6 \mathrm{~g} / \mathrm{d}$ in the control group. The increased daily intake of $\omega 6$ FAs did not negatively affect the cardiometabolic risk factors. These results are consistent with a recent paper showing the potential benefits of $\omega 6$ FAs for cardiometabolic health [42]. Additionally, the $\omega 6 \mathrm{FA} / \omega 3 \mathrm{FA}$ ratio decreased in the HMR group from 12.2 to 4.9 during the intervention. A previous study reported that patients with high cardiovascular risk such as myocardial infarction have different levels of total saturated fatty acids, $\omega 6 \mathrm{FAs}$, as well as $\omega 6 \mathrm{FA} / \omega 3 \mathrm{FA}$ ratio [43]. The decreased $\omega 6 \mathrm{FA} / \omega 3 \mathrm{FA}$ ratio might have a positive impact on the cardiometabolic risk factors, including MetS.

Our study had several limitations. Despite being a randomized controlled trial, the study was not blinded. Double-blind randomization should be warranted to investigate on cardiometabolic risk factors. Moreover, the trial comprised a relatively small number of individuals with obesity. This may lead to the fallacy of hasty generalization. Larger clinical trials are needed to generalize our findings. The wash-out period was relatively short ( 2 weeks) between visit 2 and 3. The presence of residual effects after the HMR intervention cannot be excluded. We did not adjust for all macronutrients including protein and carbohydrates, only for total energy intake, because the total number of subjects in this study was too small to adjust for many variables, as per the parsimony principle. Additionally, fat was not adjusted for because there was a large difference in intake between the two groups. Therefore, the results of this study should be interpreted with caution as they may be due to the high protein and fat content, low carbohydrate content, and lower $\omega 6 \mathrm{FA} / \omega 3 \mathrm{FA}$ ratio in the HMR, not simply due to the $\omega 6 \mathrm{FA} / \omega 3 \mathrm{FA}$ ratio. In addition, we did not investigate for saturated and monounsaturated or polyunsaturated fatty acids. A larger number of follow-up studies are needed, of which some are currently in progress. Furthermore, the relatively short intervention period necessitates a longer follow-up period. Self-reported dietary intake is often underreported; therefore, we excluded those subjects who provided fewer than $80 \%$ of the photos taken before and after meals. When interpreting the findings, it should be taken into account that estimates of underreporting were not used.

Beyond these limitations, our study had several strengths. The trained dietitian conducted dietary surveys using actual photographs, captured before and after every consumption, from the screening visit to the end of the trial. Moreover, the nutritional values were analyzed using software developed for the Korean population. The amount of nutrients and total energy was supposedly accurately estimated. The compliance of the study participants was high, excluding those who did not provide $\geq 80 \%$ of the photographs captured before and after their meals.

\section{Conclusions}

In this preliminary study, an HMR, designed with an $\omega 6 \mathrm{FA} / \omega 3 \mathrm{FA}$ ratio $<4$, in individuals with obesity led to a decreased percentage of individuals with MetS and improved cardiometabolic risk factors.

Author Contributions: H.-T.K. contributed to concept formation and design of the study protocol and interpretation of data; J.-W.L. designed the study, managed the data, and drafted the manuscript; T.H. and S.S. managed the data, suggested the analytical strategy, and performed the data analysis; Y.K., W.Y., Y.-S.K., and H.-S.Y. contributed to the concept formation and project administration. All other authors contributed to the study design and data acquisition. All authors read and approved the final manuscript.

Funding: This research received no external funding.

Institutional Review Board Statement: The study was conducted according to the guidelines of the Declaration of Helsinki, and approved by the Institutional Review Board of the Chungbuk National University Hospital (CBNUH 2020-06-021-004). 
Informed Consent Statement: Informed consent was obtained from all subjects involved in the study.

Data Availability Statement: Data described in the manuscript, code book, and analytic code will be made available upon request pending approval by the corresponding author.

Acknowledgments: This work was supported by the Korea Institute of Planning and Evaluation for Technology in Food, Agriculture and Forestry (IPET) through its future innovative food technology development program, funded by the ministry of Agriculture, Food and Rural Affairs (MAFRA) (grant number: IPET319045032HD060). The home meal replacement, essential experimental diets for the purpose of the study, was produced by Greengrassbio, Inc.

Conflicts of Interest: Y.-C.C and S.-H.S, who contributed to providing the home meal replacement, have declared conflicts of interest based on the results of the study. Other authors have no conflicts of interest to declare.

\section{References}

1. NCD Risk Factor Collaboration (NCD-RisC). Worldwide trends in body-mass index, underweight, overweight, and obesity from 1975 to 2016: A pooled analysis of 2416 population-based measurement studies in 1289 million children, adolescents, and adults. Lancet 2017, 390, 2627-2642. [CrossRef]

2. World Health Organization. Obesity and Overweight. Available online: http://www.who.int/news-room/fact-sheets/detail/ obesity-and-overweight. (accessed on 30 April 2021).

3. Blüher, M. Obesity: Global epidemiology and pathogenesis. Nat. Rev. Endocrinol. 2019, 15, 288-298. [CrossRef] [PubMed]

4. Popkin, B.M. The Nutrition Transition and Obesity in the Developing World. J. Nutr. 2001, 131, 871S-873S. [CrossRef] [PubMed]

5. World Health Organization Regional Office for the Eastern, Mediterranean. Healthy Diet; World Health Organization Regional Office for the Eastern Mediterranean: Cario, Egypt, 2019.

6. Goodhart, R.S.; Shils, M.E. Modern Nutrition in Health and Disease; Lea and Febiger: Philadelphia, PA, USA, 1980.

7. Kris-Etherton, P.M.; Harris, W.S.; Appel, L.J. Fish Consumption, Fish Oil, Omega-3 Fatty Acids, and Cardiovascular Disease. Circulation 2002, 106, 2747-2757. [CrossRef] [PubMed]

8. Kris-Etherton, P.M.; Taylor, D.S.; Yu-Poth, S.; Huth, P.; Moriarty, K.; Fishell, V.; Hargrove, R.L.; Zhao, G.; Etherton, T.D. Polyunsaturated fatty acids in the food chain in the United States. Am. J. Clin. Nutr. 2000, 71, 179S-188S. [CrossRef] [PubMed]

9. Simopoulos, A.P. Omega-6/Omega-3 Essential Fatty Acid Ratio and Chronic Diseases. Food Rev. Int. 2004, 20, 77-90. [CrossRef]

10. Simopoulos, A.P. The Importance of the Omega-6/Omega-3 Fatty Acid Ratio in Cardiovascular Disease and Other Chronic Diseases. Exp. Biol. Med. 2008, 233, 674-688. [CrossRef] [PubMed]

11. Jang, H.; Park, K. Omega-3 and omega-6 polyunsaturated fatty acids and metabolic syndrome: A systematic review and meta-analysis. Clin. Nutr. 2020, 39, 765-773. [CrossRef] [PubMed]

12. Simopoulos, A.P. Evolutionary Aspects of Diet: The Omega-6/Omega-3 Ratio and the Brain. Mol. Neurobiol. 2011, 44, 203-215. [CrossRef]

13. de Lorgeril, M.; Renaud, S.; Salen, P.; Monjaud, I.; Mamelle, N.; Martin, J.; Guidollet, J.; Touboul, P.; Delaye, J. Mediterranean alpha-linolenic acid-rich diet in secondary prevention of coronary heart disease. Lancet 1994, 343, 1454-1459. [CrossRef]

14. The Western-Pacific Regional Office of World Health Organization. The Asia-Pacific Perspective: Redefining Obesity and Its Treatment; World Health Organization Regional Office for the Western Pacific: Sydney, Australia, 2000.

15. The Korean Nutrition Society. Computer-Aided Nutritional Analysis Program (CAN-Pro) Version 5.0. Available online: http: / / www.kns.or.kr/Center/CanPro5.asp (accessed on 20 June 2021).

16. Third Report of the National Cholesterol Education Program (NCEP) Expert Panel on Detection, Evaluation, and Treatment of High Blood Cholesterol in Adults (Adult Treatment Panel III) final report. Circulation 2002, 106, 3143-3421. [CrossRef]

17. Kang, H.-T.; Kim, S.-Y.; Kim, J.; Kim, J.; Kim, J.; Park, H.A.; Shin, J.; Cho, S.H.; Choi, Y.; Shim, J.Y. Clinical practice guideline of prevention and treatment for metabolic syndrome. Korean J. Fam. Pr. 2015, 5, 375-420.

18. Matthews, D.R.; Hosker, J.P.; Rudenski, A.S.; Naylor, B.A.; Treacher, D.F.; Turner, R.C. Homeostasis model assessment: Insulin resistance and $\beta$-cell function from fasting plasma glucose and insulin concentrations in man. Diabetologia 1985, 28, 412-419. [CrossRef] [PubMed]

19. Simental-Mendía, L.E.; Rodríguez-Morán, M.; Guerrero-Romero, F. The Product of Fasting Glucose and Triglycerides as Surrogate for Identifying Insulin Resistance in Apparently Healthy Subjects. Metab. Syndr. Relat. Disord. 2008, 6, 299-304. [CrossRef]

20. Hadaegh, F.; Khalili, D.; Ghasemi, A.; Tohidi, M.; Sheikholeslami, F.; Azizi, F. Triglyceride/HDL-cholesterol ratio is an independent predictor for coronary heart disease in a population of Iranian men. Nutr. Metab. Cardiovasc. Dis. 2009, 19, 401-408. [CrossRef]

21. Wenzel, S.E. Arachidonic acid metabolites: Mediators of inflammation in asthma. Pharmacother. J. Hum. Pharmacol. Drug Ther. 1997, 17, 3-12.

22. Faber, J.; Berkhout, M.; Fiedler, U.; Avlar, M.; Witteman, B.; Vos, A.; Henke, M.; Garssen, J.; Van Helvoort, A.; Otten, M. Rapid EPA and DHA incorporation and reduced PGE2 levels after one week intervention with a medical food in cancer pa-tients receiving radiotherapy, a randomized trial. Clin. Nutr. 2013, 32, 338-345. [CrossRef] 
23. Guo, X.-F.; Li, X.; Shi, M.; Li, D. n-3 Polyunsaturated Fatty Acids and Metabolic Syndrome Risk: A Meta-Analysis. Nutrition 2017, 9, 703. [CrossRef]

24. Friday, K.E.; Childs, M.T.; Tsunehara, C.H.; Fujimoto, W.Y.; Bierman, E.L.; Ensinck, J.W. Elevated Plasma Glucose and Lowered Triglyceride Levels from Omega-3 Fatty Acid Supplementation in Type II Diabetes. Diabetes Care 1989, 12, 276-281. [CrossRef] [PubMed]

25. Ogawa, A.; Suzuki, Y.; Aoyama, T.; Takeuchi, H. Dietary Alpha-Linolenic Acid Inhibits Angiotensin-Converting Enzyme Activity and mRNA Expression Levels in the Aorta of Spontaneously Hypertensive Rats. J. Oleo Sci. 2009, 58, 355-360. [CrossRef]

26. Belchior, T.; Paschoal, V.A.; Magdalon, J.; Chimin, P.; Farias, T.M.; Filho, A.D.B.C.; Gorjão, R.; St.-Pierre, P.; Miyamoto, S.; Kang, J.X.; et al. Omega-3 fatty acids protect from diet-induced obesity, glucose intolerance, and adipose tissue inflammation through PPAR $\gamma$-dependent and PPAR $\gamma$-independent actions. Mol. Nutr. Food Res. 2015, 59, 957-967. [CrossRef]

27. James, M.J.; Gibson, R.; Cleland, L.G. Dietary polyunsaturated fatty acids and inflammatory mediator production. Am. J. Clin. Nutr. 2000, 71, 343s-348s. [CrossRef]

28. Warensjö, E.; Sundström, J.; Lind, L.; Vessby, B. Factor analysis of fatty acids in serum lipids as a measure of dietary fat quality in relation to the metabolic syndrome in men. Am. J. Clin. Nutr. 2006, 84, 442-448. [CrossRef] [PubMed]

29. Freire, R.D.; Cardoso, M.A.; Gimeno, S.G.; Ferreira, S.R.; for the Japanese-Brazilian Diabetes Study Group. Dietary Fat Is Associated with Metabolic Syndrome in Japanese Brazilians. Diabetes Care 2005, 28, 1779-1785. [CrossRef]

30. Petersson, H.; Basu, S.; Cederholm, T.; Riserus, U. Serum fatty acid composition and indices of stearoyl-CoA desaturase activity are associated with systemic inflammation: Longitudinal analyses in middle-aged men. Br. J. Nutr. 2008, 99, 1186-1189. [CrossRef]

31. Petersson, H.; Lind, L.; Hulthe, J.; Elmgren, A.; Cederholm, T.; Risérus, U. Relationships between serum fatty acid composition and multiple markers of inflammation and endothelial function in an elderly population. Atherosclerosis 2009, 203, $298-303$. [CrossRef] [PubMed]

32. Sacks, F.M.; Campos, H. Polyunsaturated Fatty Acids, Inflammation, and Cardiovascular Disease: Time to Widen Our View of the Mechanisms. J. Clin. Endocrinol. Metab. 2006, 91, 398-400. [CrossRef] [PubMed]

33. Dietary supplementation with n-3 polyunsaturated fatty acids and vitamin E after myocardial infarction: Results of the GIS-SIPrevenzione trial. Gruppo Italiano per lo Studio della Sopravvivenza nell'Infarto miocardico. Lancet 1999, 354, 447-455.

34. Tavazzi, L.; Maggioni, A.P.; Marchioli, R.; Barlera, S.; Franzosi, M.G.; Latini, R.; Lucci, D.; Nicolosi, G.L.; Porcu, M.; Tognoni, G. Effect of n-3 polyunsaturated fatty acids in patients with chronic heart failure (the GISSI-HF trial): A randomised, double-blind, placebo-controlled trial. Lancet 2008, 372, 1223-1230. [CrossRef] [PubMed]

35. Salas-Salvadó, J.; Fernández-Ballart, J.; Rosa, L.-R.; Martínez-González, M.-A.; Fitó, M.; Estruch, R.; Corella, D.; Fiol, M.; GómezGracia, E.; Arós, F.; et al. Effect of a Mediterranean Diet Supplemented with Nuts on Metabolic Syndrome Status: One-year results of the PREDIMED randomized trial. Arch. Intern. Med. 2008, 168, 2449-2458. [CrossRef] [PubMed]

36. Rauch, B.; Schiele, R.; Schneider, S.; Diller, F.; Victor, N.; Gohlke, H.; Gottwik, M.; Steinbeck, G.; Del Castillo, U.; Sack, R.; et al. OMEGA, a Randomized, Placebo-Controlled Trial to Test the Effect of Highly Purified Omega-3 Fatty Acids on Top of Modern Guideline-Adjusted Therapy After Myocardial Infarction. Circulation 2010, 122, 2152-2159. [CrossRef]

37. Writing Group for the AREDS2 Research Group. Effect of long-chain omega-3 fatty acids and lutein + zeaxanthin supplements on cardiovascular outcomes: Results of the Age-Related Eye Disease Study 2 (AREDS2) randomized clinical trial. JAMA Intern. Med. 2014, 174, 763-771. [CrossRef] [PubMed]

38. Ascend Study Collaborative Group. Effects of n-3 fatty acid supplements in diabetes mellitus. N. Engl. J. Med. 2018, 379, 1540-1550. [CrossRef]

39. Lee, P.S.S.; Dart, A.M.; Walker, K.Z.; O’Dea, K.; Chin-Dusting, J.P.F.; Skilton, M.R. Effect of altering dietary n-6:n-3 PUFA ratio on cardiovascular risk measures in patients treated with statins: A pilot study. Br. J. Nutr. 2011, 108, 1280-1285. [CrossRef] [PubMed]

40. Poreba, M.; Mostowik, M.; Siniarski, A.; Golebiowska-Wiatrak, R.; Malinowski, K.P.; Haberka, M.; Konduracka, E.; Nessler, J.; Undas, A.; Gajos, G. Treatment with high-dose n-3 PUFAs has no effect on platelet function, coagulation, metabolic status or inflammation in patients with atherosclerosis and type 2 diabetes. Cardiovasc. Diabetol. 2017, 16, 1-11. [CrossRef]

41. Siniarski, A.; Haberka, M.; Mostowik, M.; Gołębiowska-Wiatrak, R.; Poręba, M.; Malinowski, K.; Gąsior, Z.; Konduracka, E.; Nessler, J.; Gajos, G. Treatment with omega-3 polyunsaturated fatty acids does not improve endothelial function in patients with type 2 diabetes and very high cardiovascular risk: A randomized, double-blind, placebo-controlled study (Omega-FMD). Atherosclerosis 2018, 271, 148-155. [CrossRef]

42. Monnard, C.R.; Dulloo, A.G. Polyunsaturated fatty acids as modulators of fat mass and lean mass in human body composition regulation and cardiometabolic health. Obes. Rev. 2021, 22 (Suppl. 2), e13197. [CrossRef] [PubMed]

43. Siniarski, A.; Rostoff, P.; Rychlak, R.; Krawczyk, K.; Gołębiowska-Wiatrak, R.; Mostowik, M.; Malinowski, K.P.; Konduracka, E.; Nessler, J.; Gajos, G. Unsaturated fatty acid composition in serum phospholipids in patients in the acute phase of myocardial infarction. Kardiol. Pol. 2019, 77, 935-943. [CrossRef] 